\title{
Comparison of the Urodynamic Patterns of the Disorders Frequently Encountered in the Field of Pediatric Urology
}

\author{
- ( Hasan Demirkan*, ( ) Mehmet Ozgur Kuzdan** \\ *University of Health Sciences Turkey, Kanuni Sultan Suleyman Training and Research Hospital, Clinic of Pediatric Urology, Istanbul, \\ Turkey \\ **University of Health Sciences Turkey, Kanuni Sultan Suleyman Training and Research Hospital, Clinic of Pediatric Surgery, Istanbul, \\ Turkey
}

\section{Abstract}

Aim: There is still a lack of sufficient evidence-based data on the standardized urodynamic patterns of urological disorders worldwide, particularly in the childhood age group. With this study, we sought to investigate the outcomes of urodynamic studies of common disorders frequently encountered in pediatric urology practice.

Methods: Children who underwent urodynamic studies in a pediatric urology unit between March 2019 and September 2020 were included in the study. A retrospective review of data on demographic characteristics and cystometrogram findings of 266 children from the urodynamic laboratory database was performed.

Results: The diagnoses of the patients were vesicoureteral reflux (VUR) ( $n=120)$, spinal dysraphism (SD) ( $n=94)$ and day-time incontinence (DI) $(n=28)$. Twenty-four patients who had other than these diagnoses were excluded. While there was no statistically significant difference between VUR-DI cases $(p=0.31)$ and DI-SD cases $(p=0.1)$ regarding bladder compliance, it was noteworthy that bladder compliance was diminished in the SD group when compared to the VUR group $(p<0.001)$. The presence of idiopathic detrusor contraction (IDC) suggesting overactive bladder was also compared and no significant difference was found between the groups $(\mathrm{p}=0.084)$.

Conclusion: The results of our study contribute the literature for urodynamic manifestations that are still challenging to standardize in children with urologic disorders because of the variety of outcome measures and multitude of urodynamic parameters used. We also announce that the IDC is a noteworthy pattern of neurogenic as well as non-neurogenic urological disorders.

Keywords: Incontinence, spinal dysraphism, urodynamics, vesicoureteral reflux

\section{Introduction}

Urodynamic or video-urodynamic studies are widely used technical contrivances for monitoring voiding dysfunction in children with lower urinary tract (LUT) symptoms $(1,2)$. The standard urodynamic test consists of four main parts: the uroflow test, cystometrogram, electromyelogram, and voiding pressure study (3). They all at once assist in identifying the underlying urological condition in cases with LUT symptoms by making precise and objective measurements for muscle/nerve function, pressure in/around the vesica, urinary flow rates, and several other parameters (4). The recent Cochrane analysis, including seven trials, has argued that the management of children with LUT symptoms according to urodynamic investigations leads to better clinical outcomes compared to treatment based on history and physical examination (1). Subsequently, in 2015, the International Children's Continence Society (ICCS) established a standardization report on urodynamic studies of LUT in children (5). It aimed to create a uniform guideline on the measurement and documentation of urodynamic investigations in children. According to

\section{Address for Correspondence: Hasan Demirkan}

University of Health Sciences Turkey, Kanuni Sultan Suleyman Training and Research Hospital, Clinic of Pediatric Urology, Istanbul, Turkey 
the report, invasive urodynamic studies are indicated in cases of non-invasive investigation suggests obstruction, genitourinary abnormalities, neuropathic detrusorsphincter dysfunction, profound non-neuropathic detrusor-sphincter dysfunction [children with high-grade vesicoureteral reflux (VUR) and recurrent febrile urinary tract infection], or prominent post-voiding residue of undefined cause $(5,6)$.

To date, various studies have been carried out by clinicians to establish reference values for urodynamic parameters in children of various age groups $(7,8)$. However, the small number of studies, the fact that they were mostly conducted in healthy groups, and the wide age range of the participants prevent the generalization of the obtained reference values to the whole population (9). This difficulty is also due to the diversity of measurement methods in each laboratory, and hence the difficulties in standardizing and creating a universal nomogram of urodynamic outcomes. Therefore, data on the distribution of urodynamic patterns in children is still insufficient and further research is needed $(3,6,10)$.

Invasive urodynamic studies are frequently preferred in children with LUT dysfunction depending on VUR, daytime incontinence (DI), spinal dysraphism (SD), or posterior urethral valve. Therefore, we aimed to investigate the distribution of urodynamic patterns of the three diseases that are the most common indications for urodynamic studies in pediatric urology practice.

\section{Methods}

\section{Study Design and Ethical Consideration}

Following local institutional review board approval (from University of Health Sciences Turkey, Kanuni Sultan Suleyman Training and Research Hospital local ethical committee, with a number of 2020.11.205 and the date of 16/11/2020), a total of 266 children under 18 years of age who underwent urodynamic study in a pediatric urology clinic from March 2019 to September 2020 were enrolled in the study. Written informed consent was obtained from all subjects and their parents or guardians. The age, gender and diagnosis were recorded from hospital automation system. Analyses of the urodynamic patterns of patients with DI, VUR, or SD were performed retrospectively using the urodynamic laboratory database. Patients who had to receive any medication at the time of the study and refused to participate in the study were excluded. Even if any patient had to take a drug that could affect the outcome of the study, the drug was interrupted at least one week before the examination if it did not harm the patient. Before the procedure, urine culture negativity was verified.

\section{Diagnosis of Primary Diseases}

Diagnosis of primary VUR was established by voiding cystourethrography, and the severity of VUR was determined using the International Reflux Study Classification (11). Patients with secondary VUR were excluded.

The diagnosis of SD was made in the newborn period and the patients with SD underwent reconstructive surgery for the defect.

According to a report by ISSC on the standardization of terminology for LUT function, DI was defined as the leakage of urine in discrete amounts while awake intermittently (12). Patients with DI had no organic disease in their medical history.

\section{Urodynamic Procedure}

Urodynamic examinations were performed in the urodynamics laboratory by a nurse, and the results were interpreted by a pediatric urologist. A supine position on a urological table was used for each subject. The patients were monitored during the procedure. The bladders of patients were emptied by a $6 \mathrm{Fr}, 2$ lumen catheter that was placed in the urethra. Thereafter, the bladder was filled continuously at a filling rate of $10 \%$ of the expected bladder capacity with room temperature sterile saline. The expected bladder capacity was estimated according to the following formula: (age+1) $\times 30$ (5). The procedure was stopped if the patient needed to void, the presence of significant urine leakage, or $40 \mathrm{~cm} \mathrm{H}_{2} \mathrm{O}$ of intravesical pressure was detected. The residual urine volume of more than $20 \mathrm{~mL}$ at the end of the voiding phase marked the emptying disorder. The detrusor type and compliance, voided urine volume, expected bladder capacity for children, maximum value of cystometric capacity, and residual urine volume in the bladder were analyzed. Detrusor activity was characterized as normoactive, overactive, or underactive (13). Hypocompliance of the detrusor muscle was evaluated quantitively. The outcomes in the filling and voiding phases identified the storage and emptying disorders. Uroflow was performed after the procedure. Consequently, electromyography activities during micturition were measured. Urodynamic investigations were performed by a licensed urodynamic measurement system (Aymed-Locum Wireless Urodynamics System).

\section{Statistical Analysis}

Urodynamic test results were evaluated and compared based on age, gender, and etiologies. The SPSS software Version 22.0 (SPSS Inc., Chicago, IL, USA) was used for the statistical analysis. Among the descriptive statistics, mean \pm standard deviation was used for normally distributed variables, median [interquartile range (IQR)] was used for non-normally distributed variables, and percentage 
(\%) was used for categorical variables. For non-normally distributed values, non-parametric tests were used to compare the groups. T-test for independent samples was used in the comparison of descriptive statistics, the chi-square test or Fischer's exact test was used in the comparison of categorical parameters, and ANOVA was used to compare the means among three or more groups, Post-hoc evaluations were made with the Games-Howell test. $\mathrm{P}<0.05$ was considered statistically significant.

\section{Results}

There were 104 (39.1\%) boys and 162 (60.9\%) girls among the 266 patients who underwent urodynamic testing. Among the group; 120 (45.1\%) patients had VUR, 28 (10.5\%) had DI, 94 (35.3\%) had SD, and 24 $(9 \%)$ had other disorders. The mean age of the patients was $7.69 \pm 3.86$ years. Demographic features and the comparisons of the urodynamic findings of the patients with VUR, DI, and SD are summarized in Table 1.

A comparison of median maximum cystometric capacities revealed that while there was no significant difference between VUR and DI patients $(p=0.31)$, patients with SD had a lower maximum cystometric capacity than VUR and DI cases ( $p<0.001, p=0.031$, respectively).

While mean bladder compliance was lower in the SD group than in the VUR group $(p<0.001)$, there was no statistically significant difference between VUR-DI cases $(p=0.31)$ and DI-SD cases $(p=0.1)$.

Residual urine volume comparison revealed that significant residue was present in patients with SD compared with those patients with VUR or DI $(p<0.001)$. However, cases with VUR and DI showed no statistically significant difference regarding residual urine volume $(p=0.03)$.

The presence of idiopathic detrusor contraction (IDC) suggesting overactive bladder (OAB) was also compared and there was no significant difference between the groups (VUR-DI: $p=0.089$; VUR-SD: $p=0.095$; SD-DI: $p=0.66$ ).

The mean maximum detrusor pressure was significantly higher in children with SD than in children with DI and VUR $(p<0.001)$. It did not, however, show a difference in subjects with VUR and DI ( $p=0.35)$.

Voiding patterns of the study group are summarized in Figure 1. The flow patterns identified in those diagnosed with SD were no micturition in 59 (62.7\%) patients, staccato in two $(2.1 \%)$, interrupted in $14(14.8 \%)$, plato in $14(14.8 \%)$, and bell-shaped in five (5.3\%).

\section{Discussion}

Urodynamic studies are invaluable diagnostic modalities widely used in the fields of urology and pediatric urology (14). In the last quarter century, urodynamic testing has been preferred increasingly in children to reveal the underlying causes of LUT symptoms and for accurate and effective management of several urinary tract abnormalities resistant to therapy (15). Therewithal, uniform and standardized patterns of urodynamic results based on real-life data couldn't be established previously, as well as for ultrasonography or voiding cystourethrography. This study aimed to describe and compare the urodynamic parameters of the three most common pediatric urologic disorders.

$O A B$ is defined as urgency and increased daytime frequency of micturition with or without urinary incontinence according to the definition of the ICCS (12). As an abnormality in urodynamics, $O A B$ is characterized by IDC during the filling phase of the micturition cycle, which can be spontaneously or provoked (16). In a study by Xing et al. (17), an investigation of the prevalence of $O A B$ in Chinese children was reported as $9.01 \%$ (913/10 133). In a review by Franco $(18,19)$, they revealed that $O A B$ is a common problem affecting up to $12 \%$ of children. In our study, $42.1 \%$ of the group had IDC suggesting

\begin{tabular}{|c|c|c|c|c|}
\hline & VUR & DI & SD & p-value \\
\hline Patient number $(n)$ & 120 & 28 & 94 & \\
\hline Age (years), median (minimum-maximum) & $8(1-16)$ & $7(4-17)$ & $7(1-19)$ & 0.53 \\
\hline Gender, $\mathrm{n}(\%)$ Male/female & $38(31.7 \%) / 82(68.3 \%)$ & $12(42.9 \%) / 16(57.1 \%)$ & $43(45.7 \%) / 51(54.3 \%)$ & 0.096 \\
\hline Mean expected bladder storage capacity (\%) & 90.8 & 81.6 & 74.1 & \\
\hline Mean bladder compliance $\left(\mathrm{mL} / \mathrm{cm} \mathrm{H}_{2} \mathrm{O}\right)$ & $18.1 \pm 11.7$ & $14.9 \pm 12.6$ & $10.8 \pm 11.1$ & $0.001^{*}, \mathrm{a}$ \\
\hline $\begin{array}{l}\text { Residual urine volume (mL), IQR (minimum- } \\
\text { maximum) }\end{array}$ & $40(0-400)$ & $30(0-330)$ & $115(0-500)$ & $<0.001^{*}, \mathrm{~b}$ \\
\hline Presence of idiopathic detrusor contraction (n) & $46(38.3 \%)$ & $16(57 \%)$ & $50(53.1 \%)$ & 0.084 \\
\hline Mean maximum detrusor pressure $\left(\mathrm{cm} \mathrm{H}_{2} \mathrm{O}\right)$ & $17 \pm 11.4$ & $14.7 \pm 12.8$ & $48.6 \pm 31.8$ & $<0.001^{*}, c$ \\
\hline
\end{tabular}


$O A B$ in accordance with symptoms. This inconsistency was attributed to the fact that the study was conducted on a patient group having an organic pathology. In a recent cross-sectional study from China, 232 children with urotherapy-resistant $O A B$ were evaluated to assess the relationship between urodynamic study findings and urotherapy treatment response. Ultimately, it was shown that decreased cystometry bladder capacity in urodynamic investigation may suggest a poorer treatment response to urotherapy than in patients with normal bladder capacity, although urodynamic verification of overactivity is not a prerequisite for response to urotherapy treatment (20). Among the pathological findings in urodynamics, $O A B$ evaluation is an important finding that should be investigated in many diseases and in healthy children.

In 2011, researchers from Bambino Gesu' Children's Hospital of Rome suggested that urodynamic evaluation may be beneficial in the management of children with VUR by identifying those with bladder dysfunction secondary to abnormal voiding habits (21). According to their data, detrusor hyperactivity was present in $10.8 \%$ of the whole group, whereas it was significantly higher in symptomatic patients $(24 \%)$ than in the non-symptomatic group (6\%) $(p<0.05)$. In our study, despite comparing the patients with or without symptoms, we found IDC in $38.3 \%$ of patients with VUR. This high rate was in roughly concordance with the rate of \%44.7 that is in the study of Batinic et al. (22) comparing the grade of reflux and urodynamic findings of children with VUR. They revealed that children with lower VUR grades (I and II) had a higher percentage of pathological urodynamic findings than children with higher VUR grades (III and IV) (77.5 vs. 66.6\%) (22). In our cohort, data on reflux grade was not obtained.

In a study conducted with 240 patients with DI, IDC was found in 12 patients who did not respond to treatment. Since the information about the pre-treatment urodynamic studies of these patients was not provided, information about the detrusor muscle activity of all the incontinent patients in the group is not available. In a study by Elmissiry et al. (4), IDC was reported in $45 \%$ of 56 pediatric patients with refractory enuresis, which is consistent with our study. In our study, IDC was present in $57 \%$ of the subjects with $\mathrm{DI}$, and there was no significant difference between the groups. The fact that there was no significant difference in the presence of IDC in neurogenic and non-neurogenic urologic disorders provides invaluable information for clinicians in terms of their clinical approach.

Musco et al. (23) published a systematic review of all the available evidence on urodynamics predicting upper urinary tract damage in patients with neurogenic LUT dysfunction. No authors reported data on the duration of IDC in neurogenic detrusor overactivity children. In 2020, Solakhan et al. (24) evaluated the course of urinary problems in children with SD. They found the differences between bladder capacity, bladder pressure at maximal capacity, compliance, and detrusor hyperactivity at first admission and post-treatment were statistically significant $(p<0.05)$. They suggested that early follow-up of

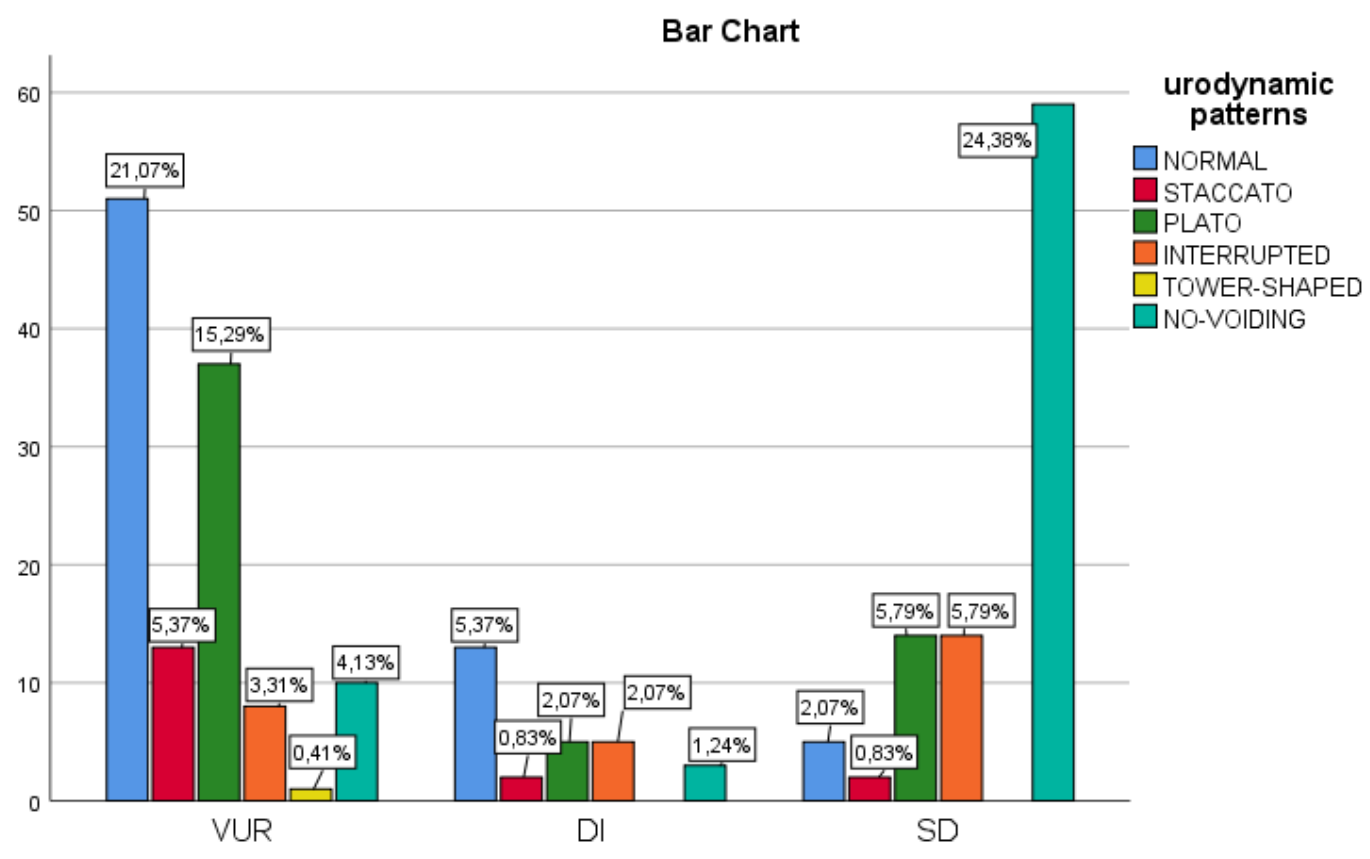

Figure 1. Micturition patterns of the groups VUR: Vesicoureteral reflux, DI: Daily incontinence, SD: Spinal dysrpahism 
urodynamics should be performed, and treatment should be carried out if necessary (24). Although our study does not discuss pre-and post-treatment urodynamic findings, it is valuable as it provides IDC frequency data for both SD and non-neurogenic patients.

Worldwide, uroflowmetry is often the sole tool performed during the initial evaluation of children with LUT symptoms. Various alterations in flow patterns are thought to indicate particular types of LUT disorders, specifically staccato flow indicating dysfunctional voiding and interrupted flow indicating detrusor underactivity. Assessing patients with uroflowmetry is of utmost importance in advancing diagnostic certainty and thereby leading to choosing the most accurate therapy (25). Because available data is limited and varied it is not entirely clear what the normal course of urinary flow in children is (26). In the literature, one of the largest series in healthy children evaluating urinary flow parameters generated uroflowmetry nomograms (27). The staccato pattern was the most common pattern seen in children with LUT dysfunctions in several studies $(25,28)$. In contrast with them, the interrupted pattern was the most common in all patient groups in our study.

Overall, urodynamic testing is a well-tolerated, invasive procedure commonly used to evaluate LUT function in children (29). However, standardization of urodynamic patterns is still a challenging issue in this age group. This is the first study in terms of revealing and simultaneously comparing the urodynamic patterns of the most frequently encountered diseases in pediatric urology daily practice. In view of our results, we suggest that IDC is worth considering in both neurogenic and non-neurogenic urologic disorders in children.

\section{Study Limitations}

Missing data on urodynamic findings of patients limits the study. In addition, analyses with larger sample groups and detailed data from urodynamic studies will be more effective for making meaningful comparisons. Since there were not an equal number of patients from each disease group in the study, homogeneity could not be achieved and statistical interpretations could only be limitedly made. Despite these limitations, the study is very valuable in terms of revealing the urodynamic patterns in common urological pathologies in children compared to adults.

\section{Conclusion}

Our findings suggest that urodynamic evaluation may play an important role in the management of children with urologic disorders by identifying those with bladder dysfunction. We think this study contributes to the literature regarding the comparison of IDC frequency for the most common disorders in pediatric urology since normal urodynamic parametric data in pediatric patients is limited. Larger, definitive randomized trials are still required to standardize the findings of urodynamic studies to determine the place for urodynamics in both the routine and individualized clinical care of pediatric patients with urologic disorders.

\section{Ethics}

Ethics Committee Approval: The ethical approval was obtained from University of Health Sciences Turkey, Kanuni Sultan Suleyman Training and Research Hospital local ethical committee, with a number of 2020.11.205 and the date of 16/11/2020.

Informed Consent: Written informed consent was obtained from all subjects and their parents or guardians.

\section{Authorship Contributions}

Concept: H.D., M.O.K., Design: H.D., M.O.K., Data Collection or Processing: H.D., M.O.K., Analysis or Interpretation: H.D., M.O.K., Literature Research: H.D., M.O.K., Writing: H.D., M.O.K.

Conflict of Interest: No conflict of interest was declared by the authors.

Financial Disclosure: The authors declared that this study received no financial support.

\section{References}

1. Clement KD, Lapitan MC, Omar MI, Glazener CM. Urodynamic studies for management of urinary incontinence in children and adults: A short version Cochrane systematic review and meta-analysis. Neurourol Urodyn 2015;34:407-12.

2. Li X, Wen JG, Xie H, et al. Delayed in toilet training association with pediatric lower urinary tract dysfunction: A systematic review and meta-analysis. J Pediatr Urol 2020;16:352.

3. Jackson EC. Urodynamics in the Pediatric Patient: When to Order, How to Interpret. Curr Treat Options Pediatr 2018;4:151-73.

4. Elmissiry M, Abdelkarim A, Badawy H, Elsalmy S, Ali GA. Refractory enuresis in children and adolescents: how can urodynamics affect management and what is the optimum test? J Pediatr Urol 2013;9:348-52.

5. Bauer SB, Nijman RJ, Drzewiecki BA, Sillen U, Hoebeke P; International Children's Continence Society Standardization Subcommittee. International Children's Continence Society standardization report on urodynamic studies of the lower urinary tract in children. Neurourol Urodyn 2015;34:640-7.

6. Arlandis S, Morán E, Martínez-Cuenca E, Bonillo MÁ, Martínez-García R, Rosier P. Adaptation to Spanish of the ICS Good Urodynamic Practices. Actas Urol Esp (Engl Ed) 2018;42:625-31.

7. Chang SJ, Chiang IN, Hsieh CH, Lin CD, Yang SS. Age-and gender-specific nomograms for single and dual postvoid residual urine in healthy children. Neurourol Urodyn 2013;32:1014-8. 
8. Chang SJ, Tsai LP, Hsu CK, Yang SS. Elevated postvoid residual urine volume predicting recurrence of urinary tract infections in toilet-trained children. Pediatr Nephrol 2015;30:1131-7.

9. Meister MR, Zhou J, Chu H, et al. Non-invasive bladder function measures in healthy, asymptomatic female children and adolescents: A systematic review and meta-analysis. J Pediatr Urol 2021;17:452-62.

10. El Desoky SM, Banakhar M, Khashoggi K, Zaher ZF, Kari JA. Voiding dysfunction in children causes, management, and prognosis: A single-center retrospective study. Saudi Med J 2021;42:869-77.

11. Lebowitz RL, Olbing $H$, Parkkulainen $K V$, Smellie JM, Tamminen-Möbius TE. International system of radiographic grading of vesicoureteric reflux. International Reflux Study in Children. Pediatr Radiol 1985;15:105-9.

12. Austin PF, Bauer SB, Bower $W$, et al. The standardization of terminology of lower urinary tract function in children and adolescents: Update report from the standardization committee of the International Children's Continence Society. Neurourol Urodyn 2016;35:471-81

13. de Jong TP, Klijn AJ. Urodynamic studies in pediatric urology. Nat Rev Urol 2009;6:585-94.

14. Tekgul S, Stein R, Bogaert $G$, et al. EAU-ESPU guidelines recommendations for daytime lower urinary tract conditions in children. Eur J Pediatr 2020;179:1069-77.

15. Drzewiecki BA, Bauer SB. Urodynamic testing in children: indications, technique, interpretation and significance. J Urol 2011;186:1190-7.

16. Fuentes M, Magalhães J, Barroso U Jr. Diagnosis and Management of Bladder Dysfunction in Neurologically Normal Children. Front Pediatr 2019;7:298.

17. Xing $D$, Wang $Y H$, Wen $Y B$, et al. Prevalence and risk factors of overactive bladder in Chinese children: A population-based study. Neurourol Urodyn 2020;39:688-94.

18. Franco I. Overactive bladder in children. Nat Rev Urol 2016;13:520-32.

19. Franco I. Functional bladder problems in children: pathophysiology, diagnosis, and treatment. Pediatr Clin North Am 2012;59:783-817.
20. Wei C, Gao J, Kou L, Liu X, Lin T, He D. Can Urodynamic Findings of Overactive Bladder Determine the Treatment Effect of Urotherapy in Children? J Coll Physicians Surg Pak 2020;30:41-5

21. Altobelli E, Buscarini M, Nappo SG, Nguyen HT, Caione P. Urodynamics investigation on children with vesicoureteral reflux identifies overactive bladder and poor compliance in those with voiding dysfunction. Pediatr Surg Int 2011;27:51722.

22. Batinic D, Miloševic D, Topalovic-Grkovic M, et al. Vesicoureteral reflux and urodynamic dysfunction. Urol Int 2013;90:480-3.

23. Musco S, Padilla-Fernández B, Del Popolo G, et al. Value of urodynamic findings in predicting upper urinary tract damage in neuro-urological patients: A systematic review. Neurourol Urodyn 2018;37:1522-40.

24. Solakhan M, Oktay K, Guzel E, Bayrak O, Guzel A. Course of Urological Problems in Children with Spinal Dysraphism: LongTerm Follow-Up Results. Pediatr Neurosurg 2020;55:101-5.

25. Wenske S, Combs AJ, Van Batavia JP, Glassberg KI. Can staccato and interrupted/fractionated uroflow patterns alone correctly identify the underlying lower urinary tract condition? J Urol 2012;187:2188-93.

26. Wilcox DT aRK. Clinical and Urodynamic Evaluation of Lower Urinary Tract Dysfunction in Children. In: AW P, editor. Campbell-Walsh-Wein Urology, 12th ed. Elsevier; 2021. p. 473-88.

27. Gupta DK, Sankhwar SN, Goel A. Uroflowmetry nomograms for healthy children 5 to 15 years old. J Urol 2013;190:1008-13.

28. Wenske S, Van Batavia JP, Combs AJ, Glassberg KI. Analysis of uroflow patterns in children with dysfunctional voiding. J Pediatr Urol 2014;10:250-4.

29. Finkelstein JB, Cahill D, Graber K, et al. Anxiety, distress, and pain in pediatric urodynamics. Neurourol Urodyn 2020;39:1178-84. 